\title{
Chromosome Studies on Acute Nonlymphocytic Leukaemia in Children
}

\author{
ROSALYN M. SLATER, ${ }^{(26)}$ HENK BEHRENDT, AND FRANS C. DE WAAL \\ Institute of Human Genetics, University of Amsterdam [R.M.S.]; Emma Kinderziekenhuis, Amsterdam, The \\ Netherlands [H.B.] and Academic Hospital of the Free University, Amsterdam, The Netherlands [F.C. de W.]
}

\begin{abstract}
Summary
Cytogenetic studies have been carried out on 17 children with acute nonlymphocytic leukaemia (ANLL). Of the 16 patients analysed at diagnosis, 11 had acquired clonal chromosome abnormalities. Four out of seven cases with acute myeloid leukaemia $\left(\mathrm{M}_{2}\right)$ had 8;21 translocations, two of which were variants. Comparisons with other data on ANLL confirmed the association between the 8;21 translocation and the younger age groups. There are indications that the Netherlands may be a high incidence area for this translocation. Differences in the type of chromosome anomalies between childhood and adult ANLL were evident suggesting that different aetiologic factors may be involved.
\end{abstract}

\section{Abbreviations}

APL, acute promyelocytic leukaemia

ANLL, acute nonlymphocytic leukaemia

FAB, French-American-British cooperative group

Standard nomenclature (12) for chromosomal abberations described in the text:

p, short arm of chromosome

q, long arm of chromosome

$+/-$, placed before the appropriate symbol indicates additional or missing whole chromosomes; placed after a symbol indicates an increase or decrease in the length of a chromosome, an arm or region of a chromosome

del, deletion

inv, inversion

mar, marker chromosome

t, translocation

Although extensive cytogenetic investigations have been carried out on acute nonlymphocytic leukaemia (ANLL) $(6,21)$, only a few reports have concentrated on the variation observed in children $(1,8,16)$. Benedict et al. (1) and Rowley (18) have suggested that the range of chromosomal anomalies in childhood ANLL is different from that found in adults. We wish to report our experience with seventeen new cases. A comparison of our data with those already described in the literature revealed cytogenetic differences in acute myeloid leukaemia between childhood and adult cases with a higher frequency of the $t(8 ; 21)$ in the younger age group. There is a possibility that the Netherlands may be a high incidence area for this translocation. Variation in the occurrence of the $8 ; 21$ translocation may also reflect the type of aetiologic agents involved in the leukaemic transformation.

\section{MATERIALS AND METHODS}

Patient material. These investigations were carried out on an unselected sample of children with ANLL who had been referred to the Emma Kinderziekenhuis (15 cases) and the Academic Hospital of the Free University in Amsterdam (2 cases) over a period of 5 years.
The different types of ANLL were classified according to the recommendations of the French-American-British (FAB) cooperative group (2).

$\mathbf{M}_{1}$, acute myeloblastic leukaemia without maturation at or beyond the promyelocytic stage

$\mathrm{M}_{2}$, acute myeloblastic leukaemia with maturation at or beyond promyelocytic stage

$\mathrm{M}_{3}$, acute promyelocytic leukaemia

$\mathbf{M}_{4}$, acute myelomonocytic leukaemia

$\mathbf{M}_{5}$, acute monoblastic leukaemia

$\mathbf{M}_{6}$, erythroleukaemia

Cytogenetic methods. Cytogenetic studies were carried out on metaphases obtained by directly harvesting fresh bone marrow aspirates and/or unstimulated blood cultures harvested at 24 and $48 \mathrm{~h}$. In two instances the bone marrow was examined both directly and after $24 \mathrm{~h}$ in vitro. All methods were carried out as previously described (22).

All metaphases were examined using Q-banding (Atebrin). Attempts were made to fully analyse at least thirty metaphases from each sample (range 30-113) (Table 1). This was not possible in three cases (MG, WR, and PS). Karyotyping was carried out according to the International System for Human Cytogenetic Nomenclature (12). An abnormal clone was defined as follows: (1) two or more metaphases with an identical structural anomaly; (2) two or more metaphases with identical extra chromosomes; or (3) three or more metaphases with an identical missing chromosome.

\section{RESULTS}

Cytogenetic studies were carried out on 16 patients at diagnosis and on one patient in relapse, the data being summarised in Table 1. Of the 16 patients studied at diagnosis, 11 had acquired clonal chromosomal abnormalities $(69 \%)$.

Acute myeloid leukaemia (FAB type $M_{1}-M_{2}$ ). No cases of $\mathrm{M}_{1}$ are studied. Four of the seven patients with $\mathrm{M}_{2}$ had an 8;21 translocation, $\mathrm{t}(8 ; 21)(\mathrm{q} 22 ; \mathrm{q} 22)$. Among these seven, patient $\mathrm{RV}$ was found to have two abnormal cell lines: the majority of cells missing a $\mathrm{Y}$ chromosome in addition to the $8 ; 21$ translocation, and a small line carrying only the translocation. A single cell with additional changes was also seen. A sex chromosome was also found to be missing in patient MGr but here, other cytogenetic variation was present with the stemline being monosomic for chromosome 9 and having an additional chromosome 17 . Two variant $8 ; 21$ translocations were seen (Fig. 1). In patient $\mathrm{MJ}$ this involved a pericentric inversion of chromosome number 8 ie., $\mathrm{t}(8 ; 21)(21 \mathrm{qter} \rightarrow 21$ q $22:: 8$ p21 $\rightarrow 8$ q $22:: 8$ p2 $1 \rightarrow 8$ pter; 21 pter $\rightarrow 21$ q $22:: 8$ q $22 \rightarrow 8$ qter $)$. The other variant, found in WR, was a three-way translocation including chromosome number 17 i.e., $\mathrm{t}(8 ; 17 ; 21)(8 \mathrm{pter} \rightarrow 8 \mathrm{q} 22:: 21 \mathrm{q} 22 \rightarrow$ 21qter; 17 pter $\rightarrow 17$ q23::8q22 $\rightarrow$ 8qter; 21 pter $\rightarrow 21$ q22::17q23 $\rightarrow$ $17 \mathrm{qter}$ ). Single cells with additional variation were also observed in patients $\mathrm{MJ}$ and WR. Two other cases had normal karyotypes on diagnosis and the final patient $\mathrm{JV}$ had a clone with +4 and +8 . 
a)
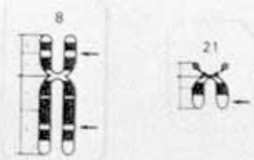

b)
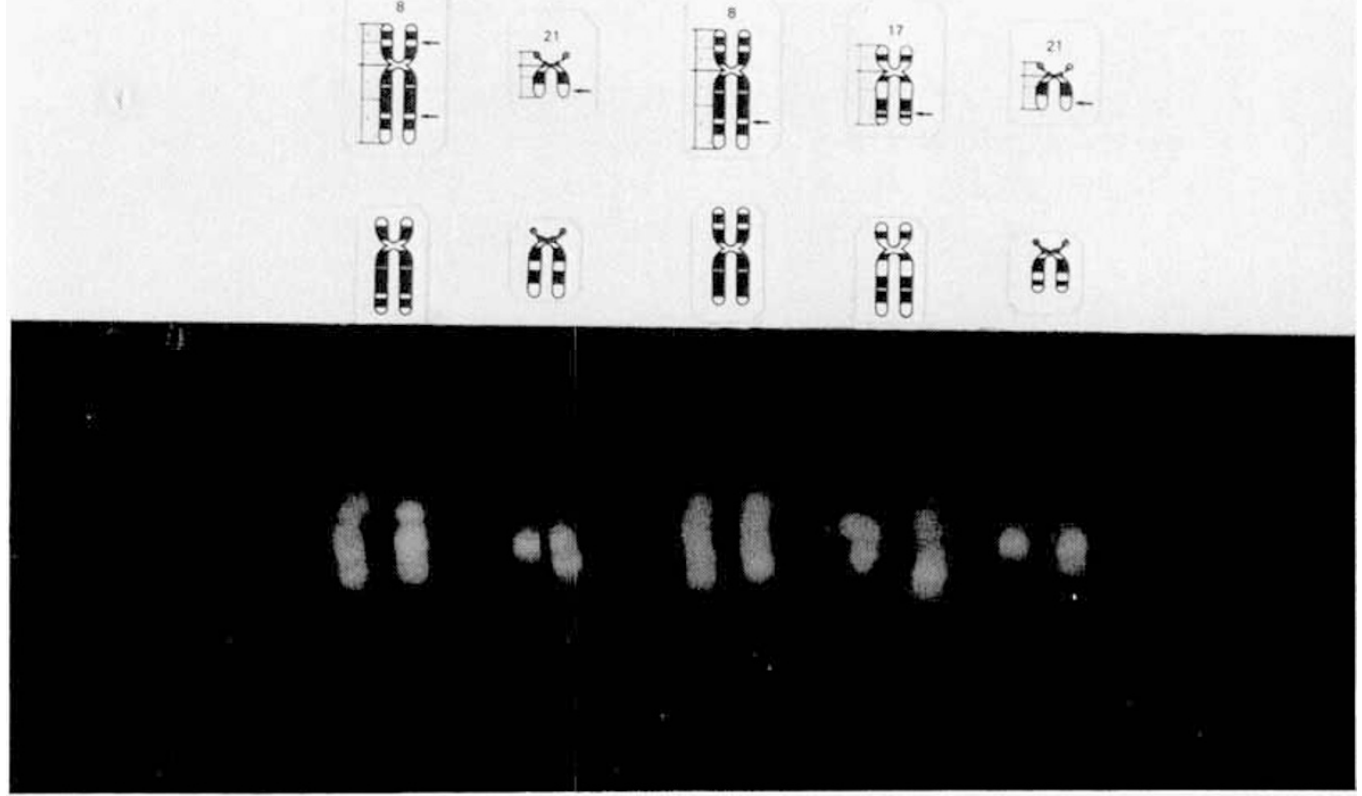

Fig. 1. Partial Q-banded bone marrow karyotypes showing variant 8;21 translocations found in two cases with $\mathrm{M}_{2}$. (a) Patient $\mathrm{MJ}$ : $\mathrm{t}(8 ; 21)(21 \mathrm{qter} \rightarrow 21 \mathrm{q} 22:: 8 \mathrm{p} 21 \rightarrow 8 \mathrm{q} 22:: 8 \mathrm{p} 21 \rightarrow 8 \mathrm{pter} ; 21 \mathrm{pter} \rightarrow 21 \mathrm{q} 22:: 8 \mathrm{q} 22 \rightarrow 8 \mathrm{qter})$. (b) Patient WR: $\mathrm{t}(8 ; 17 ; 21)(8 \mathrm{pter} \rightarrow 8 \mathrm{q} 22:: 2 \mathrm{lq} 22 \rightarrow 21 \mathrm{qter} ; \quad 17 \mathrm{pter} \rightarrow$ $17 \mathrm{q} 23:: 8 \mathrm{q} 22 \rightarrow 8 \mathrm{qter} ; 2 \mathrm{lpter} \rightarrow 21 \mathrm{qq} 22:: 17 \mathrm{q} 23 \rightarrow 17 \mathrm{qter})$.

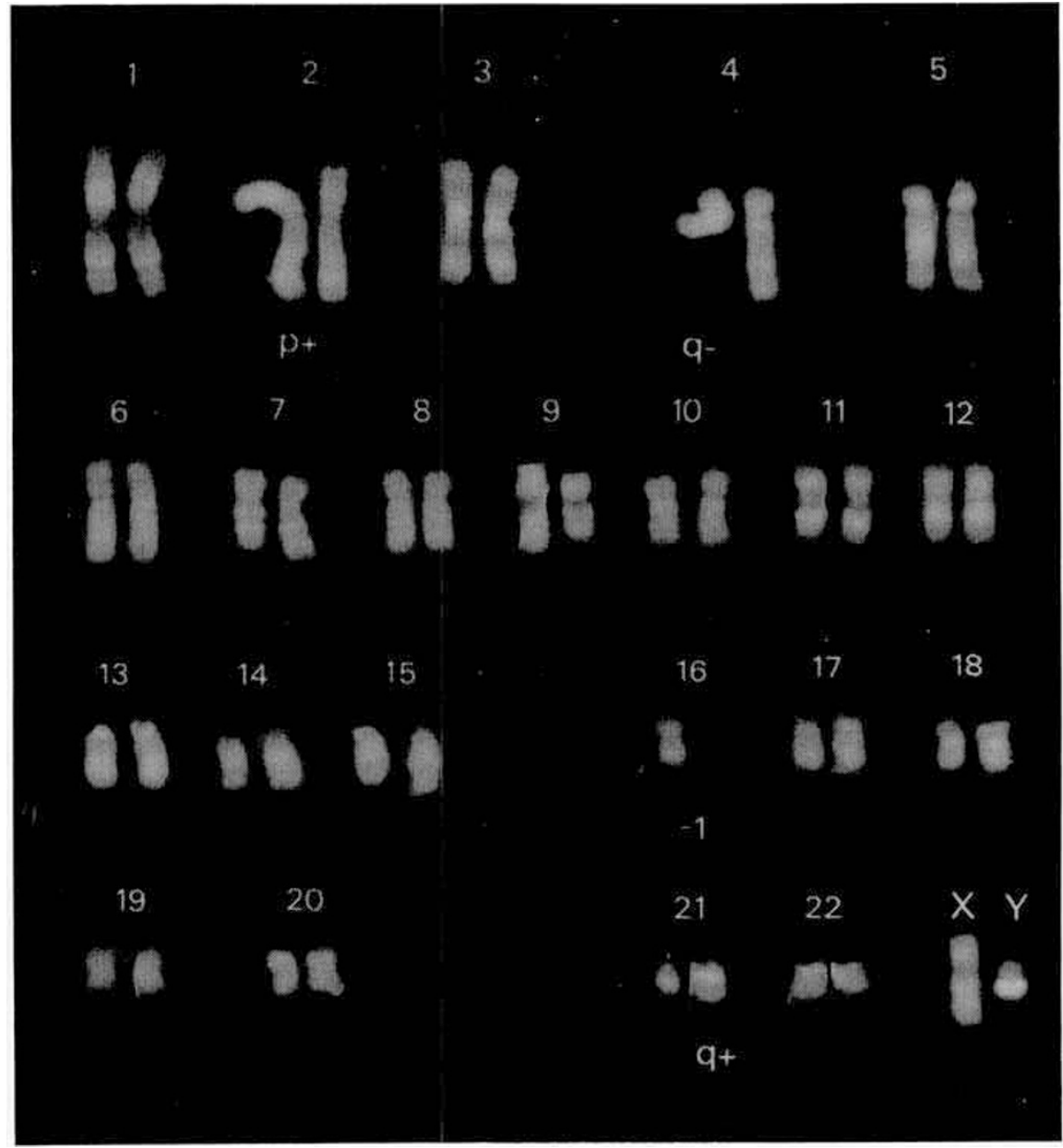

Fig. 2. Q-banded karyotype found in bone marrow cells of patient $G W$ with $M_{4}: 45, X Y, t(2 ; 4)(p 21 ; q 21),-16,21 q+$. 
400

SLATER $E T A L$.

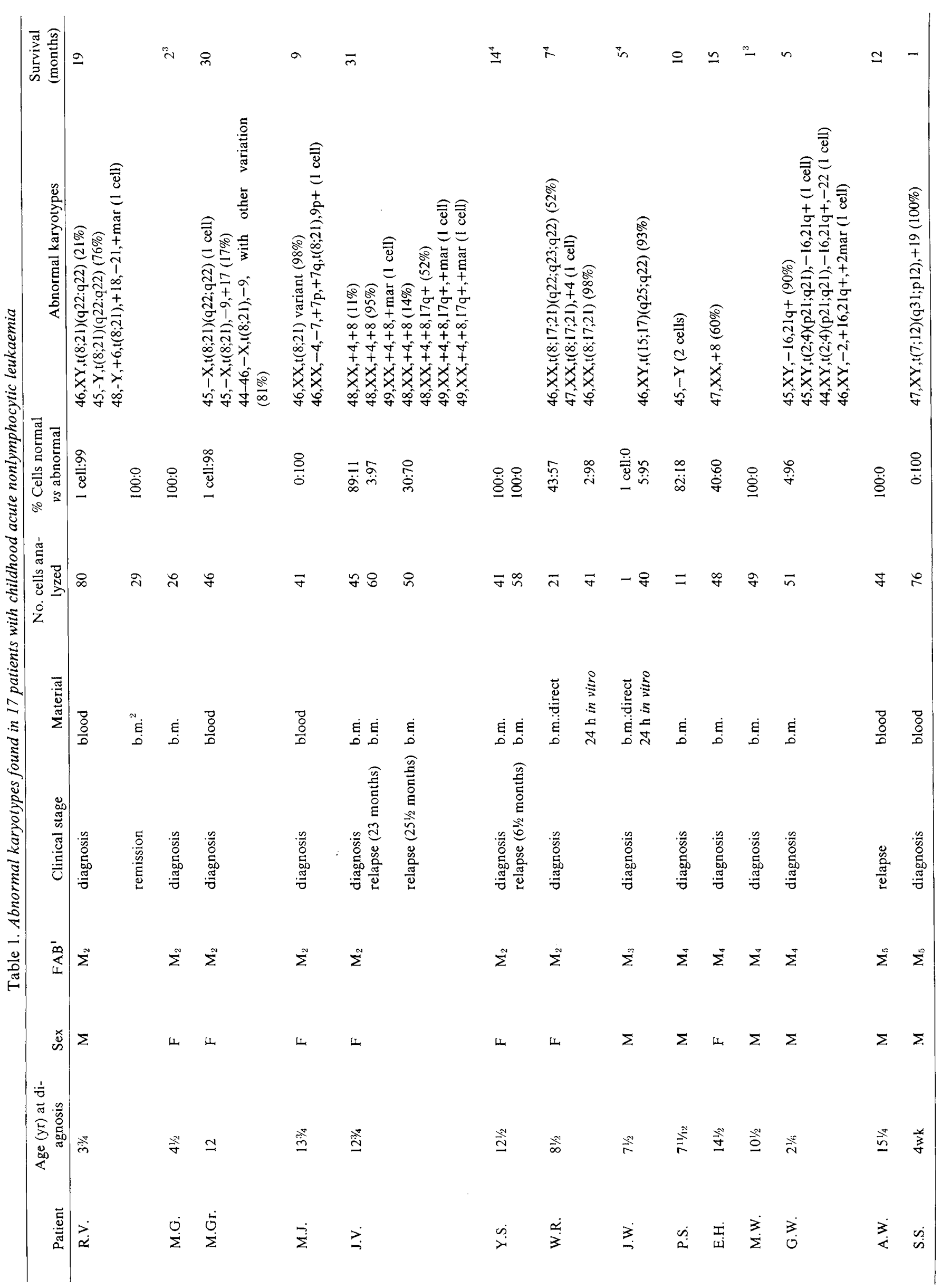


Acute promyelocytic leukaemia ( $F A B$ type $M_{3}$ ). The single patient studied had the typical $\mathrm{t}(15 ; 17)(\mathrm{q} 25 ; \mathrm{q} 22)$ and no other abnormalities.

Acute myelomonocytic leukaemia ( $F A B$ type $M_{4}$ ). Three of the four instances had abnormal karyotypes. One (EH) had a cell line with an additional chromosome number 8 , and another $(\mathrm{GW})$ was monosomic for chromosome 16 and had a $21 \mathrm{lq}+$ marker (Fig. 2). The third was patient PS where only 11 metaphases were examined but two were missing a Y chromosome, the significance of which is difficult to assess because of the small number of metaphases analysed.

Acute monoblastic leukaemia ( $F A B$ type $M_{5}$ ). The single case studied at diagnosis involved a congenital leukaemia (SS). All cells studied from unstimulated blood cultures had an abnormal karyotype: $47, \mathrm{XY}, \mathrm{t}(7 ; 12)(\mathrm{q} 31 ; \mathrm{p} 12),+19$ (Fig. 3). The relapse $\mathrm{M}_{5}$ patient (AW) had no chromosomal abnormalities.

Erythroleukaemia (FAB type $M_{6}$ ). All three cases had chromosomal variation. In one patient (PD) this was clonal and involved a possible complex translocation between chromosomes numbers $6,10,13$ and 18 , i.e., $\mathrm{t}(6 ; 10 ; 13 ; 18)(6 \mathrm{qter} \rightarrow 6 \mathrm{p} 23:: 13 \mathrm{q} 14 \rightarrow 13 \mathrm{qter}$; 10 pter $\rightarrow 10$ q $21:: 18$ q $21 \rightarrow 18$ qter; $\quad 13$ pter $\rightarrow 13$ q $14:: 10$ q $21 \rightarrow 10 q$ ter; 18 pter $\rightarrow 18 \mathrm{q} 21:: 6 \mathrm{p} 23 \rightarrow 6$ pter) (Fig. 4). Patient CK, when first examined, had two abnormal cells both trisomic for chromosomes 7,19 , and 21 , but one was missing a $Y$ and the other missing a number 3. Four abnormal cells were found in patient $E D$, each with a different karyotype.

Serial studies. These were possible in four instances. Patient RV $\left(\mathrm{M}_{2}\right)$ reverted to a normal karyotype during remission and patient YS $\left(\mathrm{M}_{2}\right)$ maintained a normal karyotype at the first relapse $61 / 2$ months after diagnosis. Clonal evolution was observed in two cases. Patient JV $\left(\mathrm{M}_{2}\right)$ was examined at the first and second relapse, 23 and $25 \frac{1}{2}$ months after diagnosis. At the first relapse the original abnormal cell line $48, \mathrm{XX},+4,+8$ was predominant and a single cell was found with an extra marker chromosome of unknown origin. Analysis of the second relapse revealed an additional abnormality in $52 \%$ of cells i.e., $48, \mathrm{XX},+4,+8,17 \mathrm{q}+$. The original cell line was still present and two other cells showed extra marker chromosomes. Patient $\mathrm{CK}\left(\mathbf{M}_{6}\right)$ was examined during three relapses, 3,5 , and 13 wk respectively after the first examination. At the first relapse, two cell lines were found in the bone marrow both with additional chromosomes 7, 19, and 21. The minor line was also missing a chromosome 20 . On the second relapse the line with 49 chromosomes was predominant in the bone marrow. By the third relapse this had almost totally replaced those bone marrow cells with a normal karyotype. Additional variation was found in the peripheral blood at this time with a small side line carrying an additional marker chromosome (Fig. 5). Other variation involving single cells was also present.

\section{DISCUSSION}

Benedict et al. (1), Hagemeijer et al. (8), and Morse et al. (16) have written papers specifically on ANLL in childhood. It is also possible to extract the childhood cases from other large series based on all age groups $(9,18)$. This information together with the data from the present study is summarised in Table 2 . Table 3 examines the chromosomal anomalies found in each FAB type. Unfortunately this classification was not used in three of the studies $(1,8,16)$ and therefore they are not included.

The $\%$ of children with acquired clonal abnormalities on diagnosis varies $50-82 \%$ (Table 2) whilst an incidence of $50 \%$ was reported for ANLL of all ages at the First International Workshop on Chromosomes in Leukemia (6). We will now compare our findings with those reported in the literature for the various $\mathrm{FAB}$ types.

Acute myeloid leukaemia ( $F A B$ type $M_{2}$ ). In the present study four of the seven patients $(57 \%)$ with $\mathrm{M}_{2}$ had an 8;21 translocation. A figure of $67 \%$ was reported by Hagemeijer et al. (9) for other childhood cases. The $t(8 ; 21)$ was also most commonly found in the 0-19 year age groups in Rowley's series but at a value of 


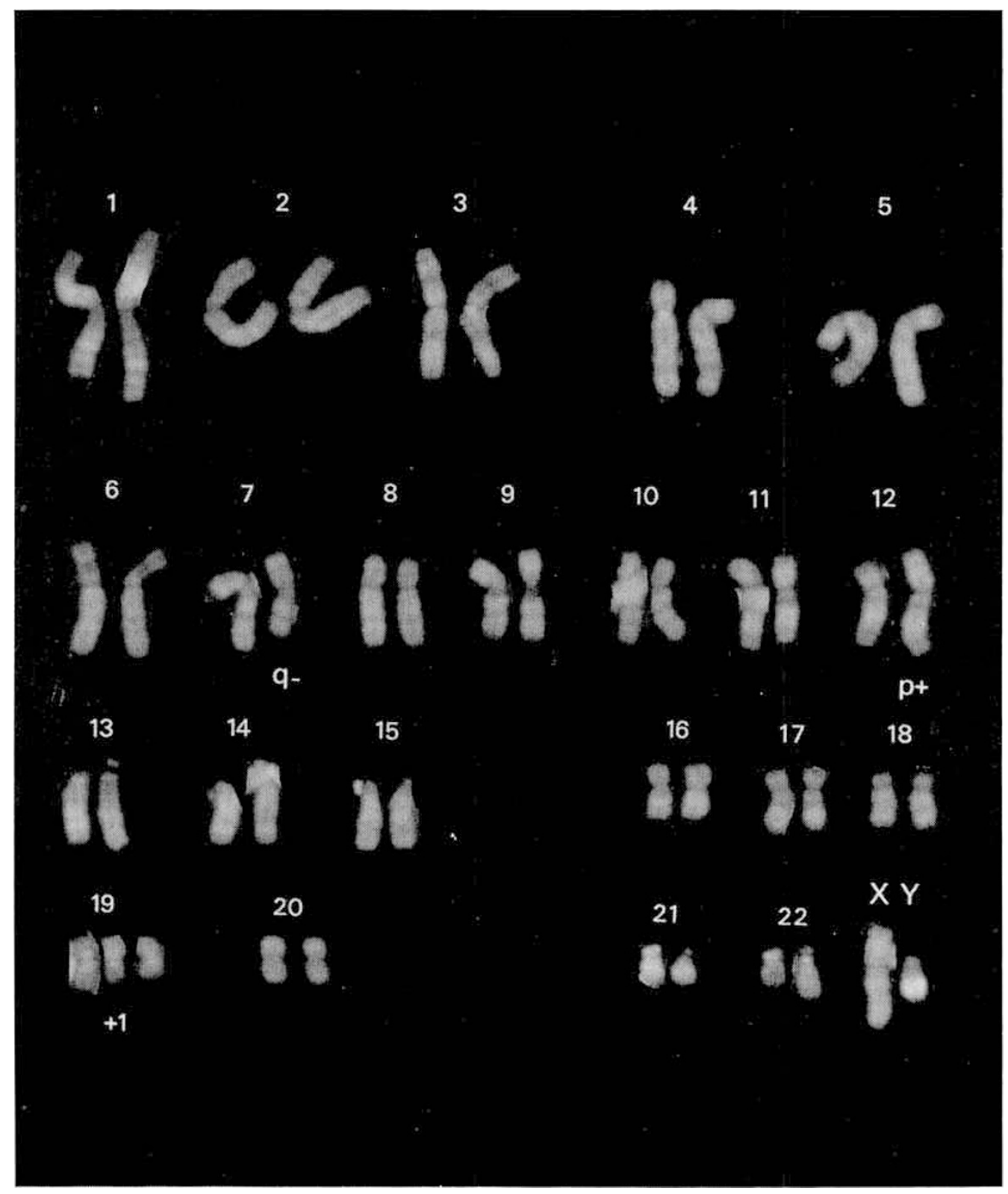

Fig. 3. Q-banded karyotype found in unstimulated blood cultures of patient $S S$ with $\mathrm{M}_{5}: 47, \mathrm{XY}, \mathrm{t}(7 ; 12)(\mathrm{q} 31 ; \mathrm{p} 12)$, +19.

$31.25 \%$ (Table 3). The Second International Workshop on Chromosomes in Leukemia (21) gave an incidence of $9.3 \%$ for all age groups. This translocation would therefore appear to be more frequently associated with $\mathrm{M}_{2}$ type childhood ANLL than with the same disease in older patients.

Geographic variation was also found in the incidence of this translocation, with Japan as a high level area (30.4\%) and Europe as a low area (London one in 35, Paris one in 23) (21). Combining our data with that of Hagemeijer et al. (9) an incidence of $61.5 \%$ for $t(8 ; 21)$ in childhood $M_{2}$ ANLL is obtained for two regional centres in The Netherlands. The series of Rowley (18) contains five childhood cases with this translocation, four of which were of Russian origin; data from Australia, Sweden, and the United States produced only one case. This suggests that geographic variation in the frequency of the $8 ; 21$ translocation also exists in childhood ANLL but with a high incidence in Europe in contrast with the findings of the Second International Workshop referred to above.

Two of the four $8 ; 21$ translocations in the present study were atypical, one showing a pericentric inversion of chromosome 8 and the other a three-way translocation of chromosomes 8, 17, and 21 . Although not common, similar variation has been previ- ously reported $(10,14,17)$. Our two nonvariant $8 ; 21$ translocations were both associated with the loss of a sex chromosome and in one of these (patient RV) the loss of the Y chromosome appeared to occur secondarily to the $8 ; 21$ translocation. Two out of four $(8 ; 21)$ childhood patients of Hagemeijer et al. (9) also had lost a sex chromosome. The Second International Workshop on Chromosomes in Leukemia (18) reported an incidence of 33\% for sex chromosome loss for patients within the $\mathrm{t}(8 ; 21)$ category.

Acute promyelocytic leukaemia $\left(F A B\right.$ type $\left.M_{3}\right)$. Of the remaining FAB types of ANLL only acute promyelocytic leukaemia (APL) has been shown to be associated with a specific chromosome abnormality $t(15 ; 17)$ which appears to have a unique geographic distribution (21). In the present series the one case examined was found to have this translocation and the patient was born in the high incident region i.e., Belgium. In three other cases of childhood APL recently reported, one was found to have the $t(15 ; 17)(7)$.

Acute myelomonocytic, acute monoblastic and erythroleukaemias (FAB types $M_{4}, M_{5}$, and $M_{6}$ ). Translocations involving the long arm of chromosome number 11 appear to be preferentially involved with $\mathbf{M}_{4}$ and $\mathbf{M}_{5}$ diagnosis in $\operatorname{ANLL}(3,4,24)$. Recently Hagemeijer et al. (11) reported three cases of acute monoblastic leukaemia $\left(\mathrm{M}_{5}\right)$ with an apparently balanced translocation 


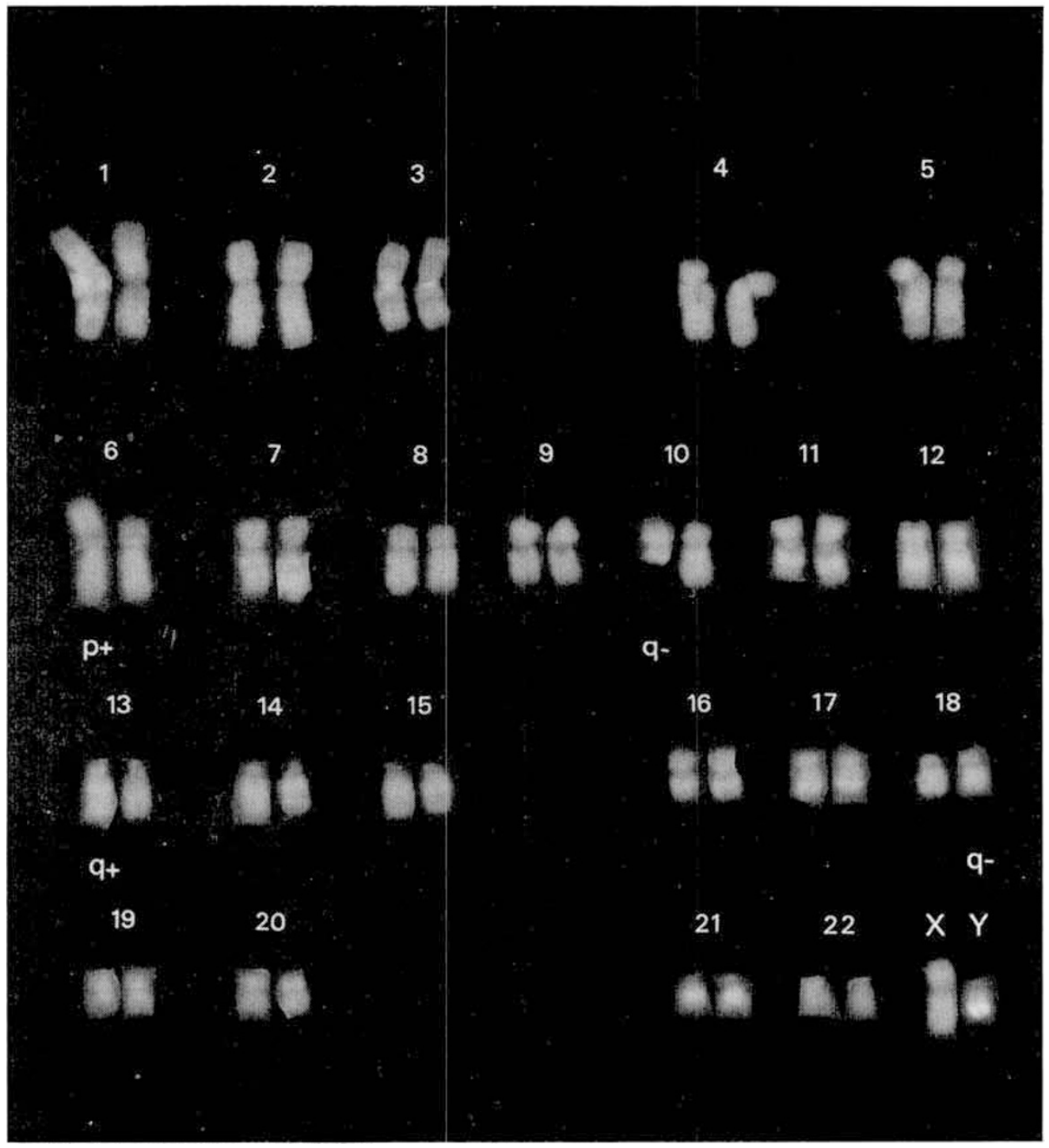

Fig. 4. Q-banded karyotype found in bone marrow cells of patient PD with $\mathrm{M}_{6}: 46, X Y, t(6 ; 10 ; 13 ; 18)(6 \mathrm{qter} \rightarrow 6 \mathrm{p} 23:: 13 \mathrm{q} 15 \rightarrow 13 \mathrm{qter}$; $10 \mathrm{pter} \rightarrow 10 \mathrm{q} 21:: 18 \mathrm{q} 21 \rightarrow 18 \mathrm{qter} ; 13 \mathrm{pter} \rightarrow 13 \mathrm{q} 14:: 10 \mathrm{q} 21 \rightarrow 10 \mathrm{qter} ; 18 \mathrm{pter} \rightarrow 18 \mathrm{q} 21:: 6 \mathrm{p} 23 \rightarrow 6 \mathrm{pter}$ ).

$t(9 ; 11)(p 21 ; q 23)$. Up until the present time these translocations do not appear to be correlated with any particular age group. In the present study the single case of $\mathrm{M}_{5}$ studied at diagnosis had no apparent abnormalities of chromosome number 11 .

Of interest is the large number of $\mathrm{M}_{6}$ patients in the combined Dutch studies compared with the childhood data of Rowley (18) (Table 3). All five of these patients had chromosomal abnormalities in the leukaemic cells.

Serial studies. Serial cytogenetic studies involving diagnosis and relapse were carried out in three patients. Additional cytogenetic variation was observed during relapse in two of these. In one patient (JV), originally with a $48, \mathrm{XX},+4,+8$ clone, the finding of an additional $17 \mathrm{q}+$ chromosome at the second relapse correlated with resistance to drug therapy. One patient (RV) with an abnormal clone at diagnosis was cytogenetically normal during remission. The present series is too small to draw any meaningful conclusions about the influence of karyotype on survival.

Other cytogenetic variation found in childhood $A N L L$. In the present study trisomy 21 was seen as a clonal anomaly in one patient (CK) but a $2 \mathrm{lq}+$ chromosome of unknown origin was also found in one other $(\mathrm{GW})$. Changes in chromosome 21 could be important in the development of acute leukaemia. The finding of an extra 21 in four of a series of 60 children with ANLL has led Rowley (19) to suggest that the increased risk of leukaemia in Down's syndrome patients may be due to the presence of an extra chromosome 21. A gain in this chromosome was also evident in children with acute lymphoblastic leukaemia who had more than 50 chromosomes in their leukaemic cells (23). As already has been shown, variation in chromosome 21 in the form of the $8 ; 21$ translocation is relatively common in ANLL. The role of specific translocations in malignant development has been discussed by Klein (13). He suggested that the genetic exchange may result in a promotor effect being exerted on the translocated segment(s). Such a mechanism could be operating in the $8 ; 21$ translocation, which could then result in the same genetic effect on the cell as an extra 21 chromosome.

In addition to the $8 ; 21$ translocation, changes in chromosomes 8,5 , and 7 , namely $+8,-5 / 5 q-$, and $-7 / 7 q-$, are relatively common in ANLL. In a series of 239 patients of all ages, Rowley (18) found that this variation occurred predominantly in the $\mathrm{M}_{1-}$ $\mathbf{M}_{2}$ category especially in cases aged 50 and above.

From the present study and those of Benedict et al. (1), Morse et al. (16) and Hagemeijer et al. (9) it can be shown that children with $\left(M_{1}-M_{2}\right)$ have lower incidence $(6 / 33)$ of variation in these chromosomes apart from the $8 ; 21$ translocation. This reinforces Rowley's findings that these changes appear to occur more commonly in older patients.

Leukaemias developing secondarily to treatment of some other disease have been shown to have a high incidence of chromosomal abnormalities, especially long arm deletions and monosomies of 


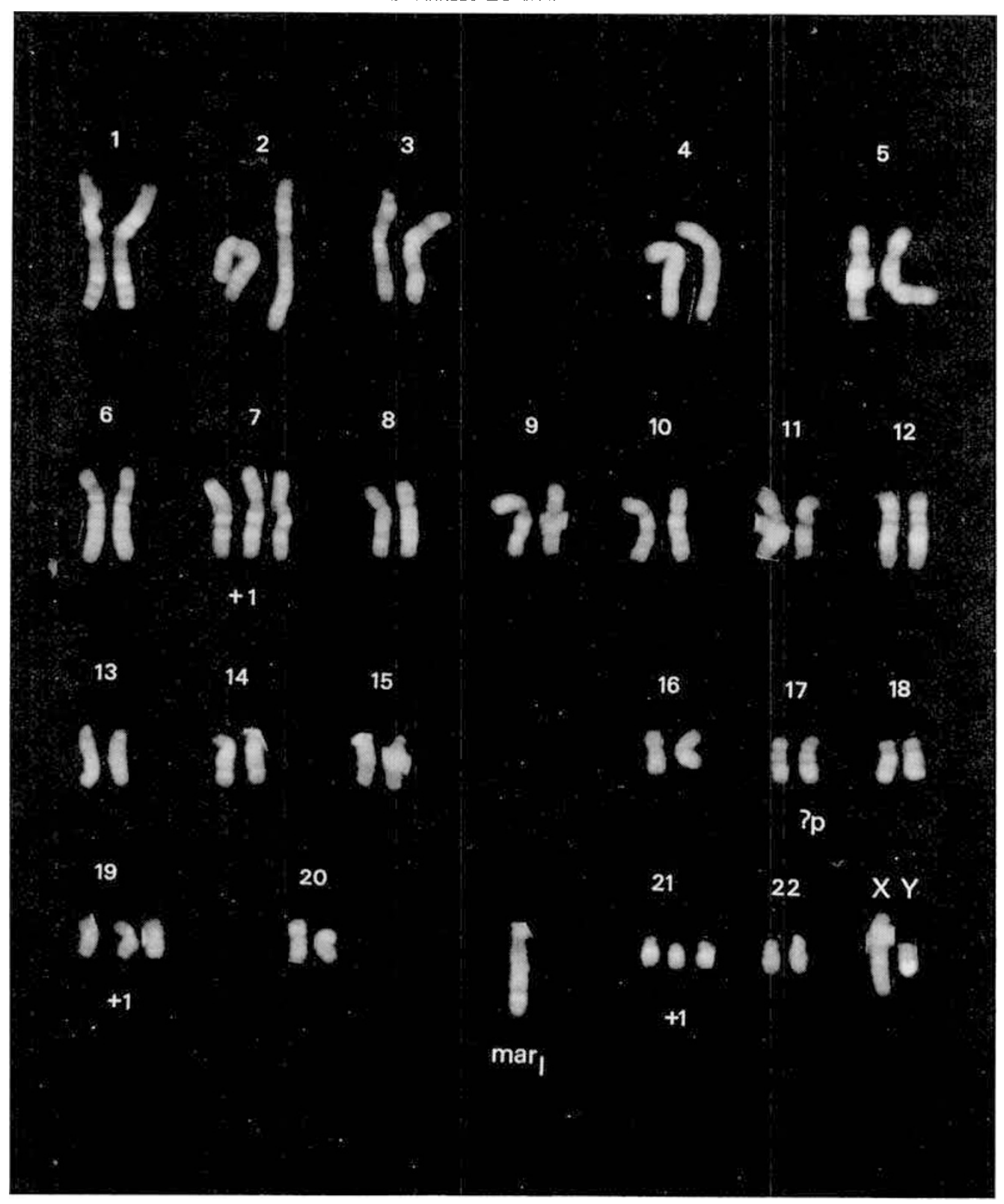

Fig. 5. Q-banded karyotype found in unstimulated blood cultures of patient $\mathrm{CK}$ with $\mathrm{M}_{6}$ in relapse: $50, \mathrm{XY},+7,+19,+21,+$ mar.

Table 2. Incidence of clonal variation in 97 cases of childhood acute nonlymphocytic leukaemia examined at diagnosis

\begin{tabular}{|c|c|c|c|c|c|c|c|c|c|c|}
\hline & \multicolumn{2}{|c|}{ Benedict et al. (1) } & \multicolumn{2}{|c|}{ Morse et al. (16) } & \multicolumn{2}{|c|}{$\begin{array}{c}\text { Hagemeijer et al. } \\
(8,9)\end{array}$} & \multicolumn{2}{|c|}{ Rowley (18) } & \multicolumn{2}{|c|}{ Present study } \\
\hline & No. & $\%$ & No. & $\%$ & No. & $\%$ & No. & $\%$ & No. & $\%$ \\
\hline Patients with clonal abnormalities & 11 & 50 & 10 & 77 & 18 & 82 & 14 & 58 & 11 & 69 \\
\hline Total number of patients & 22 & & 13 & & 22 & & 24 & & 16 & \\
\hline
\end{tabular}

chromosomes 5 and 7 (20), as do individuals with ANLL previously exposed to potential mutagenic/carcinogenic agents (15). The lower incidence of these cytogenetic aberrations in the younger age groups, at least in type $\mathbf{M}_{1}$ and $\mathbf{M}_{2}$, tends to suggest that the type(s) of aetiologic agent(s) involved in malignant transformation in these cases could be different from those acting in older populations. Differences among the incidences of the $8 ; 21$ translocation between these two age groups reinforces this argument.

Trisomy 19 was present as a clonal abnormality in two patients of the present series (Table 1: SS and CK), and in a single abnormal cell of patient ED. Four other instances have been reported in childhood ANLL $(1,9,16)$, each with additional cytogenetic variation.

Our study therefore supports the claim that the range of cytogenetic variations observed in childhood ANLL on diagnosis is different from that found in adult ANLL. There are indications that geographic variation may exist within the range of chromosomal abnormalities observed in the younger age group. Consequently there are dangers in pooling large series of data, which may disguise specific regional and age-dependant cytogenetic variations. Recently Fialkow et al. (5), using glucose-6-phosphate- 
Table 3. Clonal variation found in 56 cases of childhood acute nonlymphocytic leukaemia examined at diagnosis

\begin{tabular}{|c|c|c|c|c|}
\hline $\mathrm{FAB}$ & Karyotype & $\begin{array}{c}\text { Hagemeijer et al. } \\
(9)\end{array}$ & $\begin{array}{l}\text { Rowley } \\
(18)\end{array}$ & $\begin{array}{r}\text { Present } \\
\text { study }\end{array}$ \\
\hline \multirow[t]{7}{*}{$\mathrm{M}_{1}-\mathrm{M}_{2}$} & $-5 q / 5 q-$ & & 1 & \\
\hline & $-7 / 7 q-$ & $(1)^{1}$ & 2 & \\
\hline & +8 & & 1 & 1 \\
\hline & $t(8 ; 21)$ & $4^{1}$ & 5 & 4 \\
\hline & other & 2 & 1 & \\
\hline & normal & & 6 & 2 \\
\hline & Total & 6 & 16 & 7 \\
\hline \multirow[t]{3}{*}{$\mathbf{M}_{3}$} & $\mathrm{t}(15 ; 17)$ & & & 1 \\
\hline & $\begin{array}{l}\text { other } \\
\text { normal }\end{array}$ & & & \\
\hline & Total & & & 1 \\
\hline \multirow[t]{6}{*}{$\mathrm{M}_{4}$} & -5 & & & \\
\hline & $-7 / 7 q-$ & $2^{2}$ & & \\
\hline & +8 & $1(1)^{2}$ & & 1 \\
\hline & other & 1 & 2 & 2 \\
\hline & normal & & 3 & 1 \\
\hline & Total & 4 & 5 & 4 \\
\hline \multirow[t]{3}{*}{$\mathbf{M}_{5}$} & abnormal & 4 & 2 & 1 \\
\hline & normal & & 1 & \\
\hline & Total & $4^{3}$ & 3 & 1 \\
\hline \multirow[t]{2}{*}{$\mathrm{M}_{6}$} & $\begin{array}{l}\text { abnormal } \\
\text { normal }\end{array}$ & 3 & & 2 \\
\hline & Total & 3 & & 2 \\
\hline
\end{tabular}

'I patient with $7 \mathrm{q}-, \mathrm{t}(8 ; 21)$.

${ }^{2} 1$ patient with $-7,+8$.

${ }^{3} 1$ patient originally classified as $M_{1}$ (ref. 9), later reclassified as $M_{5}$ (ref. 10).

dehydrogenase estimations, demonstrated differences in the stem cell origin of childhood and adult ANLL and suggested that this could reflect aetiologic differences. Cytogenetic studies tend to support this hypothesis.

\section{REFERENCES AND NOTES}

1. Benedict, W. F., Lange, M., Greene, J., Derencsenyi, A., and Alfi, O. S.: Correlation between prognosis and bone marrow chromosomal patterns in children with acute nonlymphocytic leukemia: similarities and differences compared to adults. Blood, 54: 818 (1979).

2. Bennett, J. M., Catovsky, D., Daniel, M. T., Flandrin, G., Galton, D. A. G., Gralnick, H. R., and Sultan, C.: Proposals for the classification of the acute leukaemias. Br. J. Haematol., 33: 451 (1976).

3. Berger, R., Bernheim, A., Weh, H-J., Daniel, M-T., and Flandrin, G.: Cytogenetic studies on acute monocytic leukemia. Leukemia Res., 4: 119 (1980).

4. Berger, R., Bernheim, A. and Schaison, G.: Discrepancy between G and R bands. Example of an acute non-lymphocytic leukemia. Hum. Genet., 59: 84 (1981).
5. Fialkow, P. J., Singer, J. W., Adamson, J. W., Vaidya, K., Dow, L. W., Ochs, J., and Moohr, J. W.: Acute non-lymphocytic leukemia: heterogeneity of stem cell origin. Blood, 57: 1068 (1981)

6. First International Workshop on Chromosomes in Leukemia, 1979. Chromosomes in acute nonlymphocytic leukaemia. Br. J. Haematol., 39: 311 (1979).

7. Fraser, J., Hollings, P. E., Fitzgerald, P. H., Day, W. A., Clark, V., Heaton, D. C., Hamer, J. W., and Beard, M. E. J.: Acute promyelocytic leukemia: cytogenetics and bone marrow culture. Int. J. Cancer, 27: 167 (1981).

8. Hagemeijer, A., van Zanen, G. E., Smit, E. M. E., and Hählen, K.: Bone marrow karyotypes of children with nonlymphocytic leukemia. Pediatr. Res., 13: 1247 (1979).

9. Hagemeijer, A., Hählen, K., and Abels, J.: Cytogenetic follow-up of patients with non-lymphocytic leukemia II. Acute non-lymphocytic leukemia. Cancer Genet. Cytogenet., 3: 109 (1981).

10. Hagemeijer, A., Hählen, K., and Abels, J.: Cytogenetic characterization of the specific translocations $(8 ; 21)$ and $(8 ; 14)$ in acute leukemia. The Sixth International Congress of Human Genetics, Jerusalem, Israel, Sept. 13-18, 1981. Abstr. p.20.15 (1981).

11. Hagemeijer, A., Hählen, K., Sizoo, W., and Abels, J.: Translocation $(9 ; 11)(\mathrm{p} 21 ; \mathrm{q} 23)$ in three cases of acute monoblastic leukemia. Cancer Genet. Cytogenet., 5: 95 (1982).

12. International System for Human Cytogenetic Nomenclature (1978). Cytogenet. Cell Genet., 21: 309 (1978).

13. Klein, G.: The role of gene dosage and genetic transpositions in carcinogenesis. Nature, 294: 313 (1981).

14. Lindgren, V. and Rowley, J. D.: Comparable complex rearrangements involving the 8;21 and 9;22 translocations in leukaemia. Nature, 266: 744 (1977).

15. Mitelman, F., Nilsson, P. G., Brandt, L., Alimena, G., Gastaldi, R., and Dallapiccola, B.: Chromosome pattern, occupation and clinical features in patients with acute non-lymphocytic leukemia. Cancer Genet. Cytogenet., 4: 197 (1981).

16. Morse, H., Hays, T., Peakman, D., Rose, B., and Robinson, A.: Acute nonlymphoblastic leukemia in childhood. High incidence of clonal abnormalities and non-random changes. Cancer 44: 164 (1979).

17. Pasquali, F. and Casalone, R.: Rearrangement of three chromosomes (nos. 2, 8 and 21) in acute myeloblastic leukemia. Evidence for more than one specific event. Cancer Genet. Cytogenet., 3: 335 (1981).

18. Rowley, J. D.: Association of specific chromosome abnormalities with type of acute leukemia and with patient age. Cancer Res., 41: 3407 (1981).

19. Rowley, J. D.: Down syndrome and acute leukaemia: increased risk may be due to trisomy 21. Lancet, 2: 1020 (1981).

20. Rowley, J. D., Golomb, H. M., and Vardiman, J. W.: Non-random chromosome abnormalities in acute leukemia and dysmyelopoietic syndromes in patients with previously treated malignant disease. Blood, 58: 759 (1981).

21. Second International Workshop on Chromosomes in Leukemia, 1979: General Report. Cancer Genet. Cytogenet., 2: 93 (1980).

22. Slater, R. M., Philip, P., Badsberg, E., Behrendt, H., Hansen, N. E., and van Heerde, P.: A 14q + chromosome in a B-cell acute lymphocytic leukemia and in a leukemic non-endemic Burkitt Lymphoma. Int. J. Cancer, 23: 639 (1979).

23. Third International Workshop on Chromosomes in Leukemia, 1980: Chromosomal abnormalities in acute lymphoblastic leukemia: structural and numerical changes in 234 cases. Cancer Genet. Cytogenet., 4: 101 (1981).

24. Yunis, J. J., Bloomfield, C. D., and Ensrud, K.: All patients with acute nonlymphocytic leukemia may have a chromosomal defect. N. Engl. J. Med., 305: 135, (1981).

25. The authors wish to thank Margie Ayal, Maarten van Rooijen and Lineke Vassenaar for expert technical assistance, Libertine van den Berg for typing the manuscript and Rob Lutgerhorst for preparing the illustrations. We are grateful to Professor Martin Bobrey for his constructive criticism of the manuscript.

26. Requests for reprints should be addressed to: Dr. Rosalyn Slater, Institute of Human Genetics, University of Amsterdam, Sarphatistraat 217, 1018 BX Amsterdam, The Netherlands

27. This investigation was supported in part by the Koningin Wilhelmina Fonds.

28. Received for publication June 4, 1982.

29. Accepted for publication October 25, 1982. 